\title{
Problems and Countermeasures of Improving Teaching Quality in Local University \\ Yu-Feng $\mathrm{GAO}^{\mathrm{a}}$, Xi-Ping $\mathrm{MA}^{\mathrm{b} *}$ and Mei-Zhu DING ${ }^{\mathrm{c}}$ \\ College of Electrical and Information Engineering, Beihua University, Jilin China

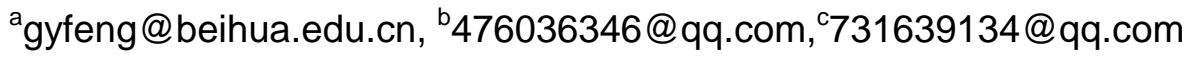 \\ *Corresponding author: Xi-Ping MA
}

Keywords: Education popularization; teaching management; examination system; Professional Title Evaluation System

\begin{abstract}
Under the new situation, universities are facing many problems. The traditional teaching cannot meet the needs of the development of high quality talents. This paper discusses the current problems of students 'popular education, teaching management, examination system, teachers' construction and the impact of style of study on teaching. Depend on above, the corresponding solutions are put forward.
\end{abstract}

\section{Introduction}

Improving the quality of teaching is the eternal theme of higher education. As early as 2003 the Ministry of Education began to implement the "higher education teaching quality and teaching reform project", after that every year to improve the quality of teaching as the focus, and later introduced the "teaching quality project" and a series of measures. "2020 Education Development Program" put "improve the quality of higher education personnel training" as the focus. This shows China focusing on improve the quality of teaching at higher education today. However, how to measure the quality of teaching, from which point of view to observe the quality of teaching, what problems exist in China, how to improve the quality of teaching, rely on to improve the quality of teaching, these questions are not one or two words can be said clearly.

\section{The current situation of higher education to improve the quality of teaching, the problems faced.}

\subsection{The issue of popular education[1]}

Since 2000,the central government has implemented the Grand College Enrollment Plan, China entered the "popular" education, college enrollment rate increased year by year, in recent years has reached more than 75\%, higher education has been transformed from elite education to mass education, the size of the university is gradually expanding. However, the quality of students in localuniversities is gradually reduced.A considerable part of the students are "wrapped in threat" into the university, their academic performance in high school is not ideal, have no good study habits, did not learn their own aspirations, ambition. These students to university only mixed diploma, qualification, and some other students despite the good college entrance examination scores, but many years of exam-oriented education has eroded their desire for knowledge and self-learning motivation, they will university life as a terminal, rest, Learning is not active, for such students, teaching in accordance with the traditional teaching methods, there is no targeted, not to attract students interest in the classroom, the absorption rate is low, teaching ineffective. Therefore, how to inspire the interest of students in the classroom, re-evoke students curiosity and devoid of curiosity, curb them from passive learning to active learning, let them willing to learn, good at learning, to become popular under the higher teaching quality is an important challenge.

\subsection{Teaching management issues}

Concept behind. For a long time, universities in teaching management, pay more attention to unity, ignoring the development of student personality, thus weakening the cultivation of students' personality and innovation ability. Specific performance in the teaching work, focusing on the 
pursuit of professional integrity of the theoretical system, do notthink more about the cultivation of student ability, only heavy slogans are not practical. Too much attention to the overall operation of the teaching, while ignoring the individual differences under normal teaching, use of one size fits all, rigid management concept is not flexible. Teaching management is only to maintain the normal operation under the conditions of standardization, blindly stick to the rules; do not think to explore new methods of management, new ideas. Teaching material, test paper andquestion library, excellent courses, etc., most of those lack of student learning, have no talent concept and employment guidance, so that students do not have great ambitions and motivation to learn, to improve the quality of teaching, Can not restrain oneself, manage oneself ${ }^{[2]}$. Many college students use counselors to manage life, learning and behavior training, however, counselors and students can not improve the quality of management and teaching combined, but the sake of discussion, only to consider their own part of the management, not able to develop from the students. And even some schools often do not focus on these areas, think these belong to the students themselves, does not belong to the scope of teaching quality management, affecting the improvement of teaching quality.

The examination management system is imperfect. Examination is a means of testing the quality of teaching, and now the university examinations in general to teachers in the classroom when students note notes for examination content, or the use of papers and large operations in the form. So that students can take advantage of the students did not go to lectures before the test Meng copy or copy the notes of other students "temporary cramming", even some individual students can get good score than the students who seriously note in the class. These situation lead to students do not pay attention to lectures, class enthusiasm is not high, or even skip classes, seriously affected the teaching effect.

\subsection{Teacher problem}

To impart knowledge and educate people is a duty to the teacher. But in recent years, under the impact of the market economy, social values change. In the face of some unbalanced policies, universities and educational administrative departments of the provisions of the call, looked pale. Some teachers to apply for scientific research projects have been appointed to focus on the project, while ignoring teaching, or in the name of scientific research is not engaged in teaching, and even become "scientists" or project government awards or school teachers are also a lot of people. Some of the so-called "quantitative" policy of "metaphysics" in the name of "scientific research", in order to subject, funding, papers, achievements and incentive measure performance, more greatly contributed to the academic Quick success trend. This policy ignores teaching and ignores the importance of basic education. In its influence, the university regardless of title, awards and teacher status and evaluation are inclined to such quantitative "scientific research", and the so-called "focus on teaching effect", often become empty words. This led to many teachers, as research hard work, depending on the teaching is a soft task. Many teachers do not really work on teaching, basic teaching skills, do not pay attain to teaching content and methods, the students are also quite unfamiliar, and even class according to the script, the get out of class turned away, never exchange; While the struggle for scientific research projects, funding, papers, patents, awards, are in droves. Teaching and scientific research are the two complementary components of cultivating high-quality talents, both of which are indispensable. The problem is that "there is a profound knowledge to have a high quality of teaching," the principle was distorted: First, researchers to pull the relationship, running the project, funding, tree signs, engage in meetings, should be reviewed has been exhausted, and no energy to take into account teaching; Second, driven by scientific research, the research results may not be more profound knowledge, give students the inspiration of the truth, Moreover, there are a lot of false scientific research, false achievements, fake patents. This "research" rounds dominance, the University has become lame, can only reel line. In this case,leaders do not know, but can do nothing. Because the university's ranking, reputation, competitiveness and social status mainly rely on scientific research achievements, and teaching quality is long-term effect. "A hundred years the tree", who also control things after a few decades it! In this way, "improve the quality of teaching" as a slogan, the school really hard only available in large amounts of money, a "landmark" and "scientific research" is not surprising, the school can only be more inclined to 
scientific research.

Wu Qidi, vice minister of the Ministry of Education, as early as May 2006, "improve the quality of teaching to deepen the teaching reform seminar," pointed out that the current teachers in the "lack of energy input, teaching enthusiasm is not high, and even individual teachers do not comply with classroom teaching Discipline "phenomenon. This phenomenon is prevalent in the university, with the pursuit of higher education institutions to upgrade and the pursuit of a comprehensive ranking requirements; the current trend has become more and more intense. And even some teaching-oriented universities are also busy pursuing research funding and achievements, and actively into science and technology competition, teachers teaching lack of energy into the phenomenon of the spread of potential.

At the same time, under the impact of the market economy, there is still a big problem in teaching ethics. Some teachers lack the sense of responsibility, do not earnestly prepare lessons and correct their homework, do not seriously guide the experiment and practice, let the students play their own, do not modify the homework, absent classes, skipping, reading, talking, sleeping. Some teachers do not pay attention to improve their professionalism, the class is not deep, not through, students can not learn the knowledge, just listen to the excitement, and even individual teachers even the teacher is not good enough to teach, The teaching content is limited to teaching materials, teaching content is poor, the classroom atmosphere is boring, so that students are very depressed, the above situation, the quality of teaching in universities, the teaching quality is not enough; How can improve the quality?[3].

\subsection{Style of study}

The phenomenon of cheating in universities is mainly manifested in the phenomenon of cheating, such as cheating in exams, substituting examinations, and plagiarism. According to reports, at a class examination, most one-half or two-thirds of the students check each other's answers. Some schools in some elective exams, students found that the use of elective courses mixed, do not know each other the opportunity to ask people on behalf of the test. Students in the graduation thesis plagiarism is serious, undergraduate graduates copy master's thesis, master copy doctoral dissertation, but also many students from the Internet to download the article as a paper turned over. Some students do a solid job of summer social practice to do the survey to write the paper score is not as good as the students in the Internet to download the article scores high, resulting in hard-working students to learn psychological imbalance, combat frustrated their enthusiasm for learning. Student leaders and teachers and managers in contact with more often in the final comprehensive evaluation or evaluation of advanced activities and other activities can give priority to honor. This is a lot of unfairness and immaturity of students often lead to distortions in values and psychological unhealthy, which are to combat the enthusiasm of students to learn and encourage the unhealthy trend, some good students become broken jar drop, individual students psychological tolerance, That life dim against the setbacks and even embarked on the extreme. All of these affect the improvement of teaching quality.

\section{The solution to the problem.}

\subsection{Strengthen the management of teaching quality.}

In the "teaching" on the basis of management, strengthen the "learning" management. First of all, colleges and universities and subordinates at all levels of party and government leaders as the quality of teaching the chairman to personally pay attention to the quality of teaching, timely study and solve undergraduate teaching work in the new situation, new problems, new challenges, and continuously promote the concept innovation, the system innovation and the work innovation, enhances the teaching quality. Second, the regular organization of teaching seminars, improve the quality of teaching teachers. Third, we should adhere to the good practices of traditional education, such as the weekly lesson preparation system; the old teachers help the news, the introduction of new teacher training system. Strengthen the teaching process control, the organization at all levels of supervision in-depth classroom, regular feedback. And strive to create a relaxed learning environment for students, respect for the law of physical and mental development of students, 
adhere to the people-oriented. Any teaching management system, measures should be conducive to fully mobilize the enthusiasm and creativity of students, is conducive to cultivating students' innovative spirit and practical ability; change teaching management functions, abandon the nanny-style, closed management, the implementation of rigid and soft, The relationship between administrative management and academic management, to establish the concept of "big management", to establish the concept of "management", to strengthen the relationship between administrative management and academic management, to establish the concept of "big management", to strengthen the class teacher system and to innovate the basic system; to correctly understand and deal with the relationship between unity requirement and individuality development, To educate people, scientific research and education, management education, service education, environmental education and organic combination

\subsection{Improve the examination system, to explore the test method to adapt to the situation [4]}

First of all, we must change the way of study of students, reflected in the way of quality education. The implementation of wide and strict out of the system, for a number of courses failed to pass the class were to repeat, credits reach the standard, to graduate can not graduate, the ability to achieve the level of graduation. The content of examination from the emphasis on knowledge to the ability to develop a series of capacity testing methods; in the examination mode can take oral, written, written on the machine, writing papers, etc., completely change the students "assault" situation; Detailed and truthful record of student performance in the classroom, the establishment of students usually learning files, in a timely manner through the counselor to inform students of their performance, to encourage students to actively performance, increase the usual results in the comprehensive results of the weight. The use of network technology to enhance the retrieval of plagiarism, serious examination discipline, which can reduce the plagiarism and other unhealthy tendencies, you can ensure that mass education, the quality of college students do not decline.

\subsection{Strengthen the construction of teachers.}

One is to strengthen the supervision and management of teacher teaching, in addition to teaching supervision, student scoring, the conditions permitting, teachers should be established video files, the teaching of the teachers discipline, teaching quality, student learning record The formation of evaluation mechanisms, and teaching and students in the bad phenomenon of timely detection and concentration efforts to solve, as the promotion of teaching and strengthening the effective management of student learning means ${ }^{[5]}$.

Second, the teachers to teach and educate people to carry out quantitative assessment, such as the number of students concerned about the depth of student research, the number of students under the guidance of class and so can be used as a quantitative reference to promote teachers to firmly establish education-oriented, The students should be treated in a fair and impartial manner. Students should be taught in accordance with their aptitude according to their aptitude. Students should be encouraged to learn from each other and encourage students to develop in an all-round way.Third, improve the professional quality of teachersas soon as possible. Teachers are an important part of improving the quality of teaching, teachers need to conduct regular business training, to provide training and study a higher level of education opportunities to improve the knowledge structure, improve the theoretical level and operational capacity, to carry out regular teaching management Academic exchange activities. The establishment of teaching evaluation of teaching mechanism, guide teachers to study business, improve teaching and research ability and practical teaching ability, reinforce the professional basis, broaden the professional caliber, continue to learn new theories, add new knowledge, improve practical ability. Guide the majority of university teachers to study teaching business, to the students responsible for, wholeheartedly to impart scientific and cultural knowledge and skills for teachers to take the following measures: (A) of the teachers according to their expertise to classify, engage in teaching engage in teaching, engage in engage in scientific research. (B) Development of scientific research teachers and teaching-oriented teachers, respectively, to develop assessment criteria and assessment index system, scientific evaluation, a reasonable evaluation; (C) the reform of the scientific research teachers and teaching-oriented teachers to change the phenomenon of scientific research; Evaluation of teaching methods, students 
on the Internet scoring, dialectical analysis of adoption. There must be a high level of teaching staff, especially those with broad vision and foresight. Good teachers, the most important thing is to inspire students to learn the consciousness and enthusiasm. Finally, form a lecture system and evaluation system of teaching satisfaction, and promote the establishment of excellent teaching style incentive mechanism. Formulate the regular teaching state inspection and monitoring implementation methods, and further improve the teaching accident identification and processing procedures. Standardize the social part-time and extra-curricular activities of teachers; improve teacher teaching assessment mechanism, establishment of dynamic online real-time teaching feedback system, at any time feedback student's supervision room for teachers to be informed. The school's website should be opened for each teacher's assessment of the teaching section, students can discuss the form of teacher evaluation at any time, at any time to identify problems at any time to correct.

\section{Conclusions}

The mission of universities is to educate and train qualified personnel for the society. On the one hand to the students to do things people, others, seek employment, to serve the community to provide the necessary psychological preparation, knowledge and ability; the other hand, but also for further study, the pursuit of higher learning and more sophisticated skills to create the necessary ladder . The so-called "delegate to fish, not fish." We are in a rapid change, the rapid development of the times. Improve the quality of teaching there is no absolute standard, as long as we can promptly correct deficiencies in the work, follow the laws of education, based on the school positioning characteristics, as long as the students' knowledge, ability and overall quality of the original on the basis of substantial progress, to meet the school location Of the training objectives of the requirements, to serve the community, that is successful.

\section{References}

[1] Yiqiu WANG.The Challenges Facing the Improvement of Teaching Quality in Colleges and Universities [J], Chinese University Teaching,2007 (2).

[2] Wang Jinren. Analysis of Classroom Teaching in the Main Problems and Countermeasures.Journal of Higher Education [J], 2011 (4).

[3] JiZhou. University Development and Scientific Management [J].China Higher Education, 2007 (5).

[4] John Aubrey Doughlass, China Futurisms: Research Universities as leaders or followers? Social Research, Vol.79, No.3, Fall2012.

[5] Huang Jinlian. University teaching management innovation and practice [J].China Construction Education. 2010, 9-10 